\title{
Eudoxus, Callippus and the Astronomy of the Timaeus.
}

Whether the astronomy of the Timaeus had any significant influence on Eudoxus' theory of homocentric spheres is a matter of contention. Some commentators deny any such influence. ${ }^{1}$ Here I argue for a view of the Timaeus' astronomy, and of Eudoxus' astronomy, whereby Eudoxus' work was as much a natural development of the Timaeus as Callippus' work was of Eudoxus. I also argue for an important interpretative principle. This is that Plato, Eudoxus and Callippus could not account for all the phenomena they were aware of, and were aware of that fact. If the Timaeus presents a prototype, Eudoxus can then be seen to develop this astronomy, making the model more sophisticated and complex while staying within the cosmological principles, and attempting to solve the key problems which were left unsolved by the Timaeus model. He does this in much the same way as Callippus made Eudoxus' model more complex and sophisticated, and attempted to solve the leading problems in that model. I also consider some further objections to a significant interaction between Plato and Eudoxus, based on supposed philosophical differences, dating, and the evidence of later commentators. I conclude that these provide no significant obstacle to considering there to be a fruitful liaison between Plato and Eudoxus.

The model proposed by the Timaeus was a significant advance on any previous model we are aware of, including Plato's model in the Republic's myth of Er.

Philolaus. $^{2}$

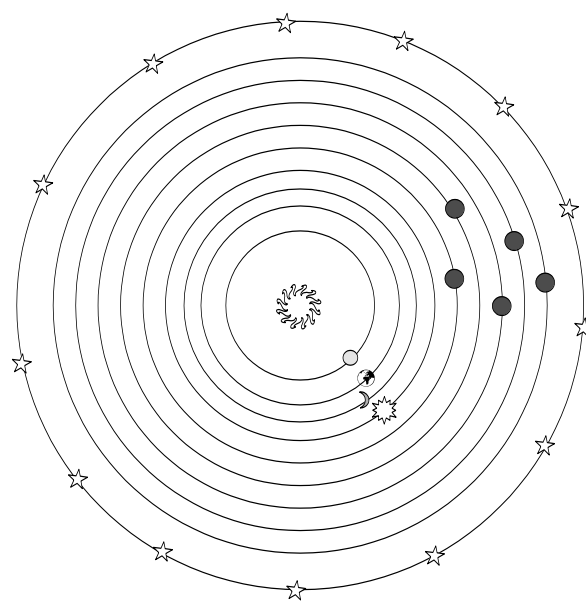

Republic, myth of Er. ${ }^{3}$

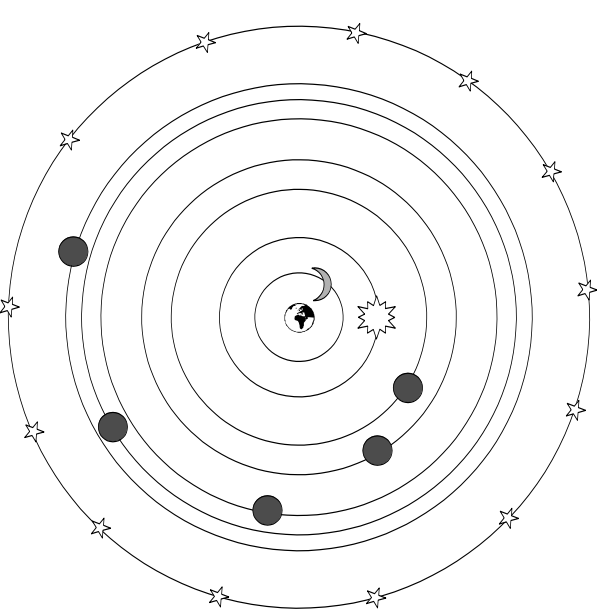


The basic problem with these models can be put like this. The earth effectively has two motions, a daily rotation and its annual orbit of the sun. ${ }^{4}$ The axes of those motions are not identical.

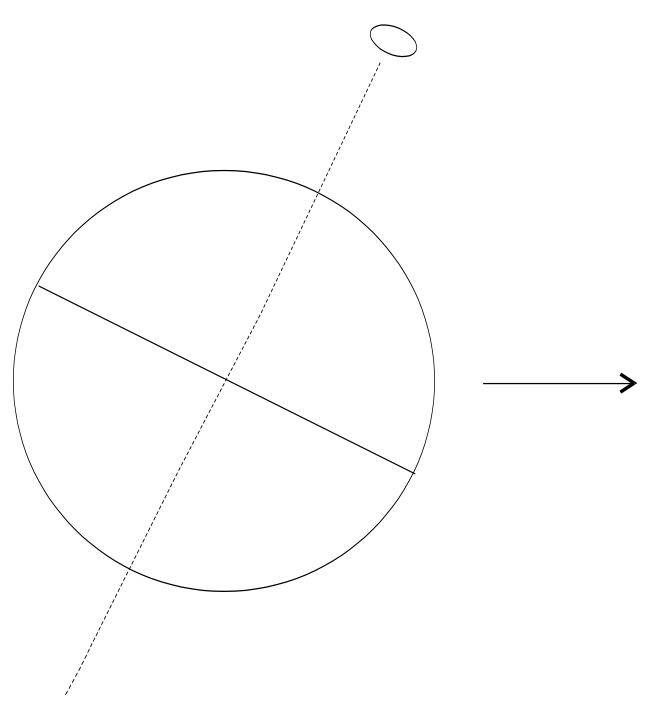

\section{Earth's axes.}

The earth's axis of rotation is offset from the plane of its orbit around the sun.

If we treat the earth as being central and stable, and so transfer these motions to the heavens, there need to be two axes of rotation, one for the fixed stars and one for the sun and the other bodies of the solar system. This, in effect, is what we get for the first time in the Timaeus.

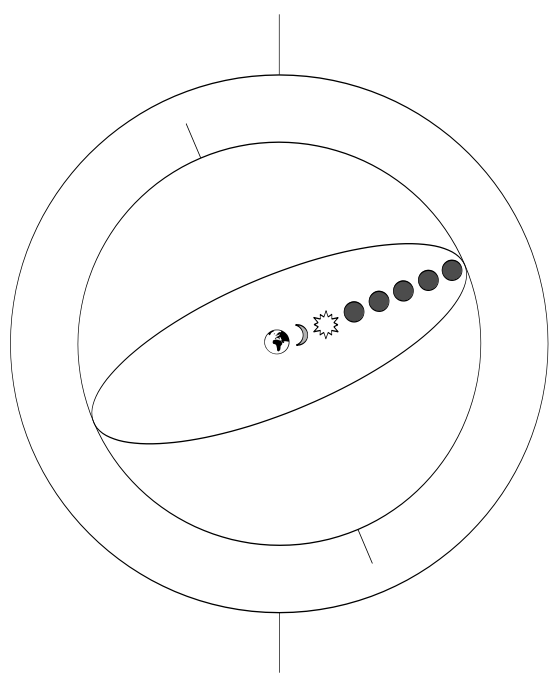

The model of the Timaeus.

The fixed stars rotate on one axis, the sun moon and planets all have an additional motion, with a magnitude specific to each, whose axis of rotation is offset from that of the fixed stars.

What can this model account for, assuming that all the motions of the heavenly bodies are regular circular motions (fixed stars) or combinations of regular circular motions (sun, moon, and planets) ? If 
one observes the position of the sun setting on the horizon, this changes during the year from a maximum north or south of west at solstices and due west at equinoxes. If one observes which star rises at the point at which the sun set, the sun moves approximately one degree a day against the background of the fixed stars. The Timaeus model accounts very well for these phenomena, and will also have the planets in motion relative to the fixed stars along the same path as the sun. ${ }^{5}$

The sun's motion relative to the background of the fixed stars.

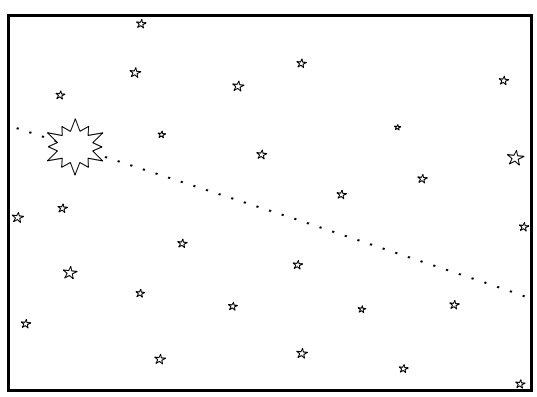

\section{The position of the sun at} sunset.

\begin{tabular}{lcc}
$\begin{array}{l}\text { Winter } \\
\text { Solstice }\end{array}$ & Equinoxes & $\begin{array}{r}\text { Summer } \\
\text { Solstice } \\
\text { 13 }\end{array}$ \\
\hline 23.5 & Due West & 23.5
\end{tabular}

What the Timaeus model could not explain (assuming regular, circular motion (RCM)) was:

(1) The retrograde motions of the planets.

(2) Any deviation from the path of the sun by the moon or planets.

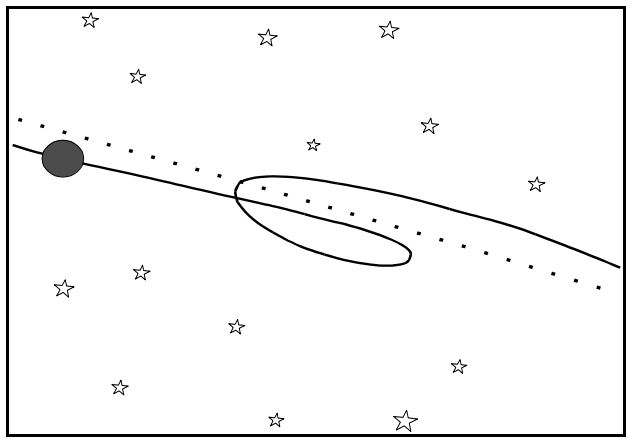
The retrograde motion of the plantes raltive to the fixed stars.

While the sun moves in one direction on a straight line known as the ecliptic, the planets can occasionally (appear to) reverse their motion, and they deviate from the ecliptic (change their latitude). The band of latitude which the five naked eye visible planets move in is known as the zodiac. Some ancients, beginning with Eudoxus, believed that the sun deviated in latitude from the line through the centre of the zodiac (a commonly used ancient term, abbreviated here to 'zodiac midline'). The Timaeus also could not explain: 
(3) The inequality of the seasons. One might expect the times between solstices and equinoxes to be equal, but in fact they are not as solstices and equinoxes are used to define the seasons, this disparity is known as the inequality of the seasons.

(4) The relation of Mercury and Venus to the sun. In distinction to the other planets, Mercury and Venus are always seen relatively close to the sun. ${ }^{6}$

(5) The frequency of eclipses (is earth, sun and moon are in one plane, as the Timaeus has them, then there will be solar and lunar eclipses once a month).

The model of the Timaeus, which has the planets moving in regular circular motion in one plane (if we ignore their daily motion) cannot account for the occasional backward motion of the planets relative to the fixed stars nor can it account for any deviation in latitude.
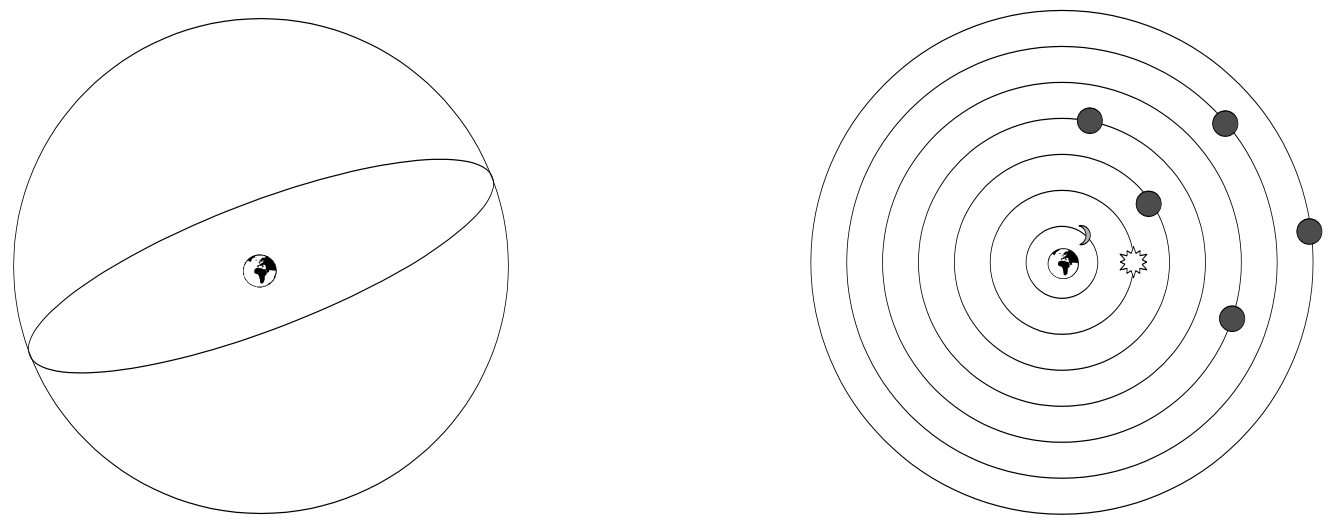

Clearly there is an issue of how many of these phenomena Plato was aware of, which we shall come back to in due course.

Given that the Timaeus model seems rather weak in explaining some relatively evident phenomena, are we justified in assuming $\mathrm{RCM} ?^{7}$ Timaeus $34 \mathrm{a}$ and $40 \mathrm{~b}$ tell us that the motions of the cosmos as a whole, and those of the fixed stars are unwandering. ${ }^{8}$ There cannot then be a metaphysical problem with the regular motions of the heavens (i.e. that which is visible and bodily can move in a regular manner). ${ }^{9}$ If the 'wanderings' of the planets constitute time (39c), and the planets, sun and moon are the 'guardians of time' (38c), then unless Plato envisages a non-uniform passage of time the motions of the heavenly bodies are regular. ${ }^{10}$ For there to be a contrast between time and eternity, all that is required is that time moves while eternity does not. Time can move in a perfectly regular manner, as would seem to be implied by $37 \mathrm{~d}$ (time as a movable image of eternity, moving according to number) and 38c (the 'wanderers' come into being to define and guard the numbers of time. The contrast 
between the fixed stars and the planets is simply that the planets have orderly motion relative to the fixed stars. If it is possible to calculate the 'perfect year' (39d) again the motions of the heavens must be orderly. Finally, Timaeus 47 a tells us that:

"God devised and gave to us vision in order that we might observe the rational revolutions of the heavens and use them against the revolutions of thought that are in us, which are like them, though those are clear and ours confused, and by learning thoroughly and partaking in calculations

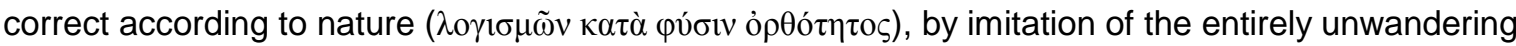

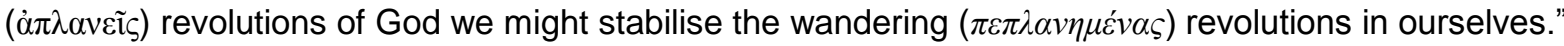

So the planets wander in the sense that they have motion relative to the fixed stars, but do not wander in the sense of having irregular motion. This is similar to the position of the Laws and Epinomis, ${ }^{11}$ but different from the Republic and Politicus. ${ }^{12}$ It is interesting to note that while both the Republic and the Politicus have the cosmos rotating on a pivot, the Timaeus has the cosmos free floating. ${ }^{13}$

\section{III}

There is though a problem with simply attributing RCM to the Timaeus, which is that we are told:

"The morning star [Venus] and the star sacred to Hermes [Mercury] he placed in an orbit

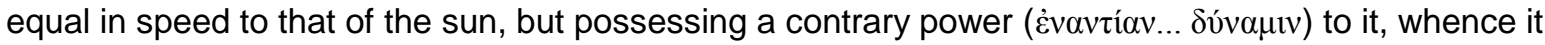
is that the sun, the star of Hermes and the morning star overtake and are overtaken by each other."

Some commentators have sought to extend the influence of the contrary power beyond this application to Mercury and Venus. ${ }^{15}$ The argument is this. Plato was aware of retrogression. Retrogression cannot be accounted for with the Timaeus model assuming RCM. If we apply the contrary power to all the planets, then the Timaeus can account for retrogression. However, as no deviation in latitude is envisaged here, earth sun and moon are all permanently in one plane and so there will be solar and lunar eclipses once a month. We might seek a further application of the contrary power, or we might question one premise of the argument. Was the model of the Timaeus 
supposed to account for all the phenomena Plato was aware of ? We might also ask: Were the models of Eudoxus and Callippus supposed to account for all the phenomena that they were aware of ? Simplicius tells us that:

"These [unrolling spheres] of Eudoxus' school do not save the phenomena, not only those that were found later, but also those known before and recognised by them."16

The three phenomena Simplicius cites are that (1) Venus and Mars appear at times much brighter than at others (2) there is variation in the apparent size of moon (3) there are variations in the type of solar eclipses relating to the apparent size of the moon. ${ }^{17}$ Should we expect Plato to be different in this respect from Eudoxus and Callippus ? If so we need an argument, and a fairly strong one, that Plato believed he had accounted for all the phenomena he was aware of in the Timaeus. No one has yet provided one, and I do not see the basis for one in the Timaeus or elsewhere.

\section{IV}

Which phenomena was Plato aware of ? Clearly he was aware of equinoxes and solstices. Timaeus $47 a 5$ tells us that:

"Sight of day and night, of months and the revolving years, of equinoxes and solstices

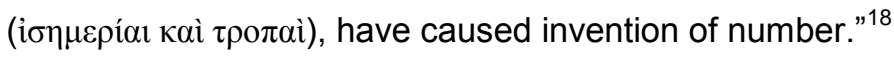

The most interesting passage though is $40 \mathrm{c}$ :

"The dances of these stars and their juxtapositions $(\pi \alpha \rho \alpha \beta o \lambda \dot{\alpha} \varsigma)$ with one another, the circling

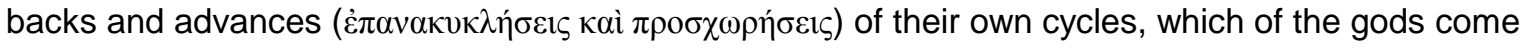

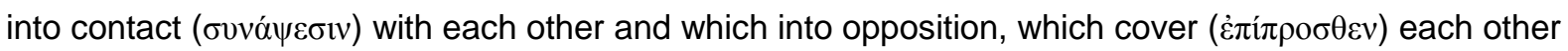

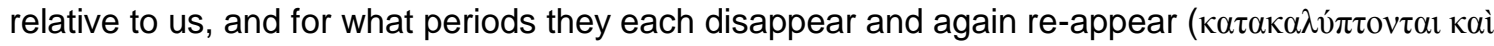
$\pi \alpha ́ \lambda ı v \dot{\alpha} v \alpha \varphi \alpha ı v o ́ \mu \varepsilon v \alpha) . "$ 
Plato would appear to be aware of retrogression. That would certainly be the most natural reading of

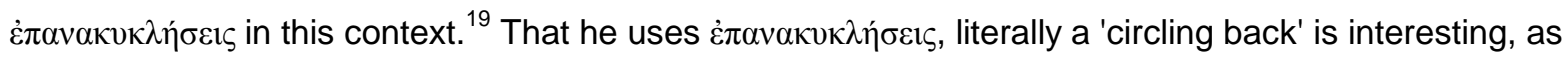
planets do not directly reverse their course but undergo deviation in latitude during retrogression, typically creating loops. ${ }^{20}$

Plato may also have a good knowledge of what happens when planets pass each other, depending on whether he uses different words to refer to one or several phenomena here. When planets pass each other, there are three things which may happen. They may pass each other with sufficient distance between them that they remain two distinct objects. They may 'touch' each other, such that they appear to be one brighter object. One may pass in front of the other, occluding it. Now

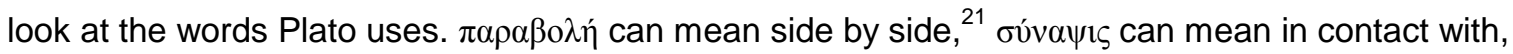
and $\dot{\varepsilon} \pi i \pi \rho \circ \sigma \theta \varepsilon v$ before, in the sense of screen or cover. Plato may well be aware of these three separate phenomena.

Possibilities for planets passing each other in the zodiac.
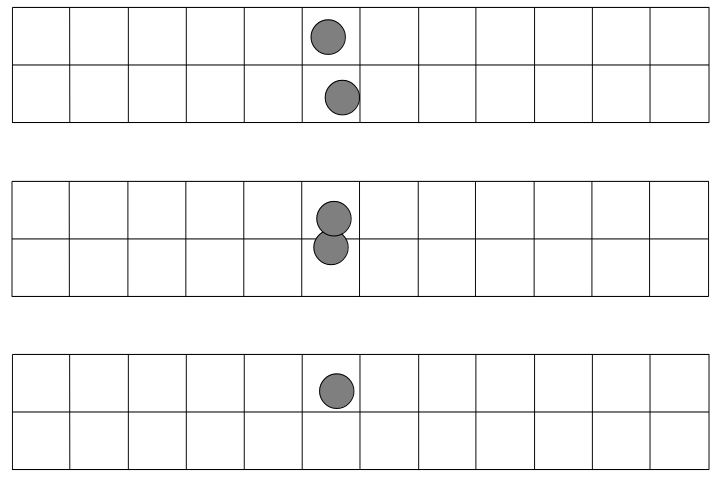

The key point here is that Plato was aware that the planets could have different latitudes, if he was aware of different passing phenomena or that planets 'circled back' during retrogression.

Plato was aware of Mercury and Venus 'overtaking and being overtaken by' the sun, from Timaeus 38d. He may well also be aware of another phenomenon, which is that Mercury and Venus are not visible when they are close to the sun. They disappear from view as they approach the sun and re-appear on the far side. The middle/ passive $\kappa \alpha \tau \alpha \kappa \alpha \lambda u ́ \pi \tau o v \tau \alpha \iota$ meaning to veil oneself or be veiled, is interesting in relation to this phenomenon. 


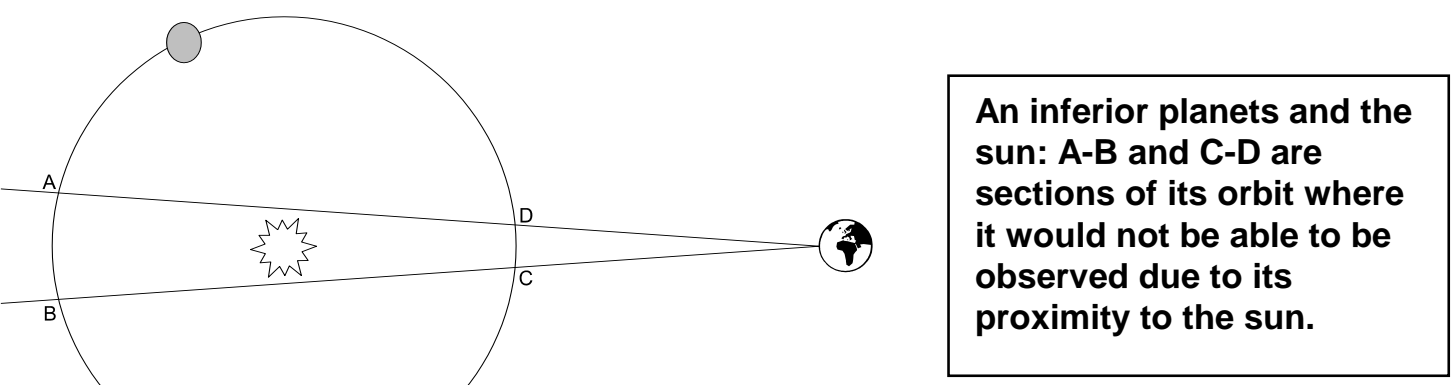

Finally, at Epinomis 978d7, the moon is said to appear larger and smaller, in a context which indicates that apparent size is being referred to rather than phase.

\section{V}

There is a problem with extending the contrary power, conceived of as self motions, to all the phenomena Plato was aware of. Clearly we can make the astronomy of the Timaeus arbitrarily good, though at the expense of a great deal of its explanatory and predictive power. We can also completely wreck RCM. Retrograde motion spoils it backward and forward along the orbits, if there is deviation in latitude then RCM fails in another way, and if the moon near and far RCM fails in a third way. Given the emphasis placed on regular circular motion in the Timaeus, I cannot believe this was Plato's intention.

How ought we to treat the contrary power then? There is a phenomenon which relates to Mercury and Venus alone, and the contrary power is mentioned solely in the context of Mercury and Venus. Mercury and Venus have bounded elongation. While the other planets may be seen at any angle to the sun, Mercury and Venus always stay relatively close to the sun and have maximum angles at which they are seen relative to the sun. This is because Mercury and Venus are inferior planets, that is their distance from the sun is less than that of the earth. 
Mercury and Venus, as inferior planets (being closer to the sun than the earth) have bounded elongation (are seen only up to certain angular separations from the sun). The superior planets can be seen at all angles.

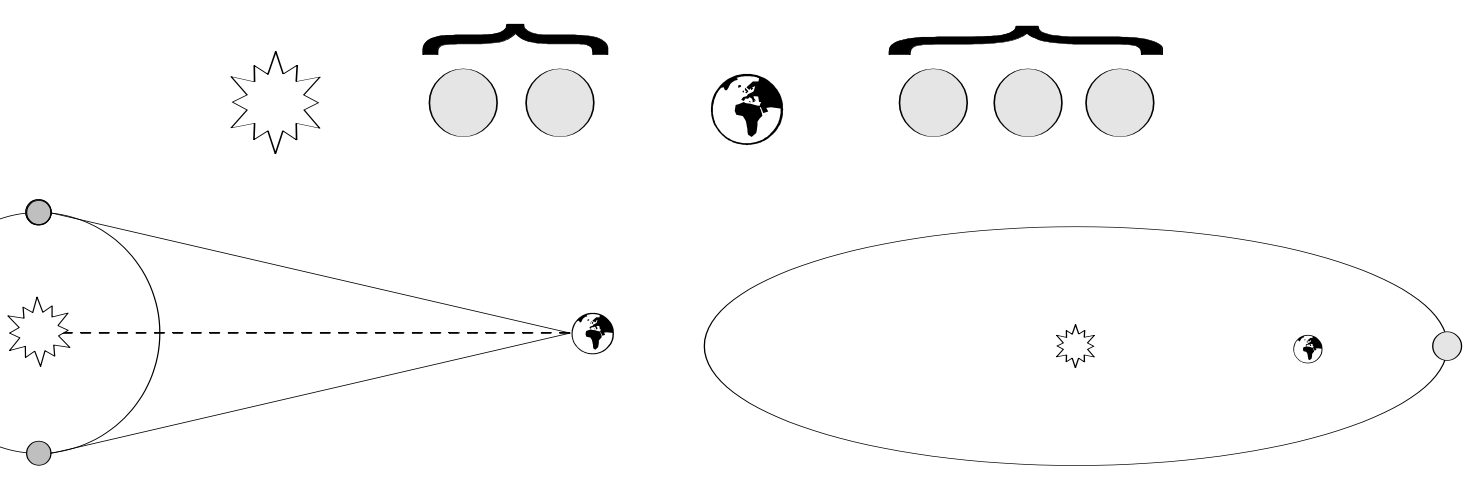

An important point to recognise here is that Mercury and Venus 'overtaking and being overtaken by' the sun does not necessarily involve retrograde motion. Mercury and Venus can move less quickly than the sun without their motion being retrograde relative to the fixed stars. ${ }^{22}$ What grounds do we have for extending the contrary power to other phenomena ? Clearly the principle that Plato believed this model could account for all the phenomena he was aware of will not do. But what criteria do we have for selecting which other phenomena to apply the contrary power to, and which not?

Where does this leave us ? It would seem that there are several phenomena which Plato was aware of and cannot be accounted for by the Timaeus model. So perhaps it is best to consider the Timaeus model as a prototype. It was a prototype of models where regular circular motions were combined with offset axes of rotation. This interpretation means the Timaeus is strong on cosmological principle but weak in what its astronomy can account for. Does the contrary power itself break the cosmological principles? Not if we follow Taylor's view that the passage merely notes the fact that Mercury and Venus have interesting behaviour relative to the sun but does not attempt to explain it. ${ }^{23}$ Even given the weakness of the astronomy of the Timaeus, it was still a considerable and significant improvement on the Pythagoreans and the Republic. Because of the use of offset axes generating motion for the sun, moon and planets along the ecliptic.

In favour of this view is that one of the main purposes of the Timaeus is to give a teleological cosmology. We might then expect the Timaeus then to be stronger on cosmological principle than astronomical detail. That too seems to be the line taken by the Laws and Epinomis. ${ }^{24}$ Simplicius' report that Plato set a challenge of saving the phenomena by regular, circular and ordered motion also sensible and plausible on this view. 
Before we consider the relation of Plato and Eudoxus, let us consider the relation of Eudoxus and Callippus. Eudoxus' system had three spheres each for sun and moon and 4 spheres each for the five planets, and one for the fixed stars. The inner spheres for each planet produced a figure of eight shape, known as the hippopede, which when combined with the motions of the first two spheres could, at least in theory, produce retrograde motion. If centres of the hippopedes of Mercury and Venus were located in the sun, the Mercury and Venus would have bounded elongation.

Callippus produced a system of 5 spheres for the sun and the moon. The standard explanation is that the extra spheres for the sun give an approximation of the inequality of the seasons, and those for the moon give a similar approximation of differences in the moon's orbital velocity, neither effect being explicable on Eudoxus' model. Callippus also produced 5 sphere models for Mercury, Venus and Mars, staying with 4 sphere models for Jupiter and Saturn. While one can get tolerable approximations of the retrograde motion of Jupiter and Saturn from Eudoxus' model, one cannot for Mercury, Venus and Mars. ${ }^{25}$

Firstly, there is an important point about models and knowledge of the phenomena here. Are we to believe that Callippus was aware of the problems with Eudoxus' model while Eudoxus was not? That seems to me most improbable, especially as the inequality of the seasons, discovered by Euctemon and Meton was reasonably well known at this time. Secondly, this seems an eminently reasonable historical reconstruction. Viewed this way, Callippus' model develops that of Eudoxus into something more sophisticated and complex and solves some of the inherent problems. One might also look at the way we construct the later history of Greek astronomy, in relation to the development of epicyclic astronomy as an attempt to improve on homocentric spheres, and the subsequent invention and application of, eccentric and equant.

Let me now offer a simple minded history of the development of homocentric sphere astronomy. Firstly, the Pythagoreans proposed regular circular motion in one plane around a central fire. Plato in the Republic offered a similar, but geocentric picture. The Timaeus provides us with regular circular motions offset at angles to each other, with two motion models for sun, moon and planets. Eudoxus develops this with three sphere models for sun and moon and four motion models 
for the planets. Callippus then gives us five motion models for the sun, the moon, Mercury Venus and Mars and four motion models for Jupiter and Saturn.

\begin{tabular}{|l|l|l|l|}
\hline $\begin{array}{l}\text { Plato, Republic. } \\
\text { Philolaus. One axis. }\end{array}$ & $\begin{array}{l}\text { Plato, Timaeus. } \\
\text { Two axes. }\end{array}$ & $\begin{array}{l}\text { Eudoxus. } \\
\text { Three and four axes. }\end{array}$ & $\begin{array}{l}\text { Callippus. } \\
\text { Four and five axes. }\end{array}$ \\
\hline & & & \\
\hline
\end{tabular}

A more sophisticated history might focus on the problems solved and phenomena accounted for by each model. Callippus, it would appear, picks up on the soluble weak points of Eudoxus' model, the lack of retrogression for some planets and the variations in orbital velocity of the sun and moon. Similarly, it would seem, Eudoxus picks up precisely the weak points in Plato's Timaeus model. We get attempts to generate retrograde motion, if hippopedes were centred in the sun for Mercury and Venus then we get bounded elongation and the overtaking and being overtaken phenomenon, we get deviation from the ecliptic, and we get, on the most likely construction, a decent theory of eclipses.

\section{VII}

There is a debate concerning the velocities of the second and third spheres for the moon in Eudoxus' system. The equator of the second sphere is the ecliptic, while the third sphere is offset at a small angle to the second, $5^{\circ}$ in the case of the moon. ${ }^{26}$ According to Simplicius, ${ }^{27}$ the third sphere rotates much more slowly than the second. However, if we transpose the velocities for the second and third 
spheres for the moon, we get a much better match with the phenomena. ${ }^{28}$ This is the line generally taken by modern reconstructions after the work of Ideler and Schiaperelli. ${ }^{29}$ The problems with the Aristotle/ Simplicius account are that (i) lunar latitudes would change very slowly (depending on how slowly the third sphere moves), when in fact they go through a full cycle in one month (ii) eclipses would occur in bunches one month apart as the moon slowly crossed the ecliptic, then would not occur for a long time (again depending on the slowness of the third sphere), before there was another bunch as the moon recrossed the ecliptic, quite contrary to observed eclipse patterns. ${ }^{30}$

\section{The Aristotle/ Simplicius}

interpretation - the second sphere (highlighted) rotates more swiftly than the third.
The modern interpretation - the third sphere (highlighted) rotates more swiftly than the second.
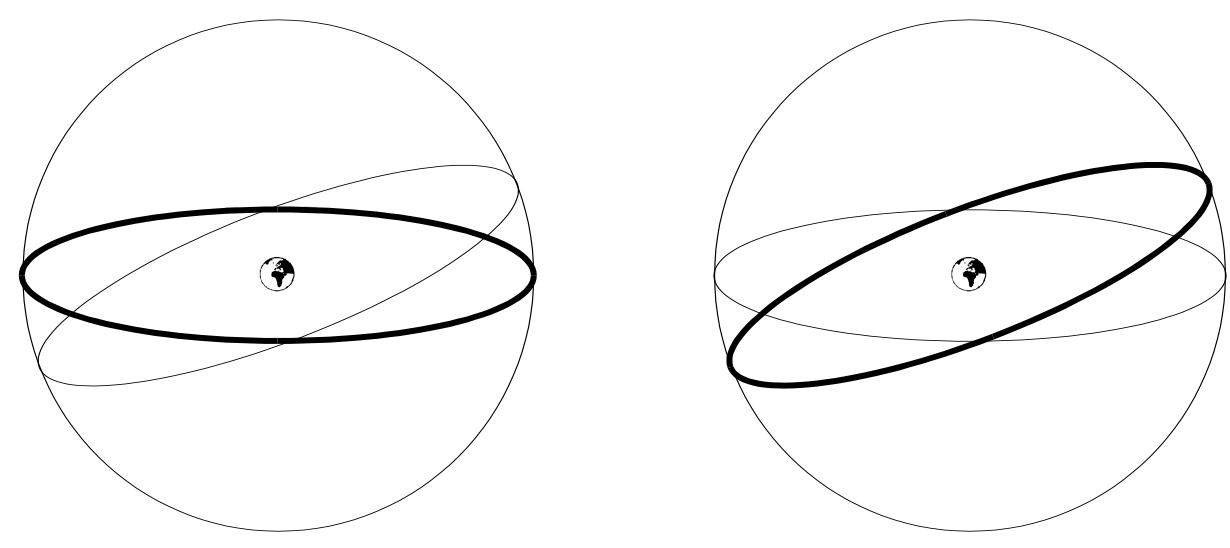

The great advantage of the modern interpretation is that it gives, for the time, an excellent lunar theory, especially if we suppose the second sphere to rotate once every 18.6 years. ${ }^{31}$ Not only would it give a reasonably good account of lunar latitude, the nodes, the points where the moon crosses the ecliptic, would gradually move. This would give the basis for a good theory of lunar eclipses.

Dicks has challenged modern consensus, arguing that we ought not to attribute such a sophisticated understanding of the moon so early, and that we ought not to be so cavalier with the clear texts of Aristotle and Simplicius. ${ }^{32}$ Given what I have argued about whether Plato, Eudoxus and Callippus could account for all the phenomena they were aware of I have some sympathy with that. I believe Dicks is correct in criticising some commentators, most notably Heath and Dreyer for attributing too great an understanding of lunar motions to Eudoxus and Callippus. However, we need to not attribute a full understanding of the regression of lunar nodes to Eudoxus and Callippus. If they 
set out to create a lunar theory with a tolerable analysis of lunar latitudes and eclipses, then Eudoxus' three sphere model seems a very natural place to start. Their knowledge might have been fairly rudimentary. They might have a rough familiarity with the cycle of lunar latitudes, know that eclipses always take place close to the line through the middle of the zodiac, and that successive eclipses occur in different parts of the zodiac. What we call the regression of the nodes might well be a consequence of the three sphere theory, which we (anachronistically) pick out as the key element. Eudoxus may not have been aware of the concept of a node, or of the concept of the regression of the nodes. ${ }^{33}$ Certainly it is more likely that he began from a rudimentary knowledge of the phenomena than a knowledge of the regression of the nodes. Mendell argues that:

"If Eudoxus did not have the reported interest in capturing the revolution of the nodes, it becomes curious why he needs three spheres instead of two, with the second sphere at an angle to the ecliptic." 34

In essence I agree with Mendell, though I am a little more cautious about attributing the conception of nodes, or regression of nodes to Eudoxus. Rather I would put matters like this. If Eudoxus was not interested in lunar latitudes, why did he have a sphere offset to the zodiac at all ? If he was not in some way interested in a tolerable theory of eclipses, why did he have a three sphere model for the moon $?^{35}$

For my purposes, all I require is that Eudoxus was interested in producing some sort of a theory of lunar eclipses and latitudes that was better than that offered by the Timaeus. Interestingly, Mendell has recently argued that if we give up some assumptions about the speeds of rotation of the second and third spheres, it is mathematically possible to have a tolerable theory of lunar latitudes and eclipses even on the Aristotle/ Simplicius interpretation. ${ }^{36}$ On balance, I would still opt for the modern interpretation. Against the standard Aristotle/ Simplicius interpretation, recent work on Aristotle has shown that he was very much an 'amateur astronomer', and that he was quite capable of such misunderstandings. ${ }^{37}$ Simplicius, although he was a good deal sharper in these matters, was not immune from error and may have been following Aristotle's authority if he thought Aristotle implied this. Mendell's suggestion, though ingenious and mathematically possible, would seem to involve some unlikely values. 
One problem we face is that we have very little material on the values used by Eudoxus and Callippus in their models. ${ }^{38}$ We have to make assumptions based on likely values and what we believe Eudoxus and Callippus were trying to do, and clearly a good deal of our reconstructing is underdetermined. $^{39}$ There are good reasons, as I have argued, for believing that the Timaeus model was a prototype. What this paper does (where the reconstruction is underdetermined) is reconstruct Eudoxus' system such that his work is a plausible and natural development of the Timaeus prototype and Callippus' work is a plausible and natural development of Eudoxus'.

One final thought on Eudoxus' solar theory. The sun was supposed to deviate from the line through the centre of the zodiac by $0.5^{\circ}$. According to Hipparchus ${ }^{40}$ and Simplicius ${ }^{41}$ the motivation was that the sun does not always rise at the same place at summer and winter solstices. Given that the probable value used for the line through the middle of the zodiac was $24^{\circ}$, and the problem of determining the exact time of solstices, that seems quite plausible. Just suppose though, as a piece of speculation, that Eudoxus was interested in solar eclipses. In the absence of a knowledge, or indeed any reliable estimate of the relative sizes and distances of earth, sun and moon, one way of accounting for the fact that there are fewer solar eclipses than lunar ones might be to give the sun a small motion in latitude, which might also help to explain the partial nature of some eclipses. ${ }^{42}$ This is $^{\text {in }}$ not to suggest that Eudoxus had a full theory of solar eclipses, just that he might have been interested in explaining, at least qualitatively some of the more evident phenomena, and that this might help to explain the hypothesised deviation in solar latitude.

\section{VIII}

While we have the evidence of Aristotle and Simplicius linking Eudoxus and Callippus, what evidence do we have linking Plato and Eudoxus ? Simplicius tells us that:

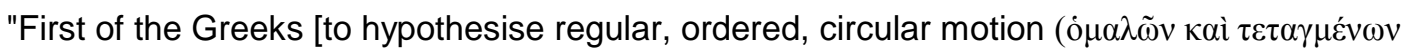

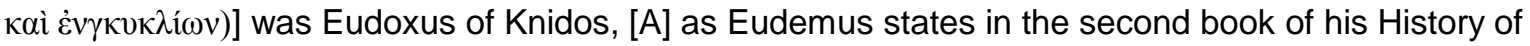
astronomy, and so too Sosigenes having taken this from Eudemus, $[\mathrm{B}]$ and as Sosigenes says, Plato had posed the following problem for those engaged in such studies: "Which hypotheses of motion

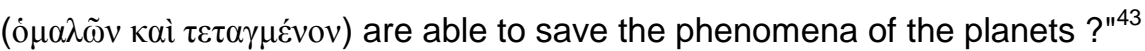


As there has been considerable debate concerning this passage, it is also worth quoting what Simplicius says a few pages later:

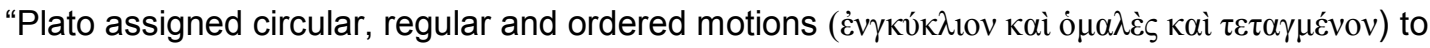
the heavens, and offered this problem to the mathematicians, which hypotheses of regular, circular

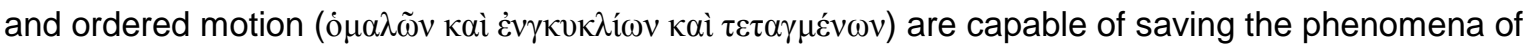
the planets, and first Eudoxus of Knidos produced the hypothesis of the so-called unrolling spheres." ${ }^{44}$

Some commentators have worried that while Simplicius cites Eudemus and Sosigenes in $[A]$, he cites only Sosigenes in $[\mathrm{B}]{ }^{45}$ Thus we only have Sosigenes' testimony for $[\mathrm{B}]$, which may be a later construction, and so the evidence for Plato having set this problem is thin. I agree with Vlastos that Sosigenes may have failed to acknowledge Eudemus, or that Simplicius may simply have failed to acknowledge Sosigenes' acknowledgement for stylistic reasons, and so we cannot infer from the Simplicius passage that $[\mathrm{B}]$ was not in Eudemus. ${ }^{46}$ I would add that we cannot lay any great store in Simplicius' pedantry ${ }^{47}$ as he gives four different formulations of the type of motion required, ${ }^{48}$ and that Simplicius repeats the attribution of this problem to Plato without any sense of it being problematic. As Simplicius gives these various formulations, it may be that what he reports is not a direct quote from Plato, though I would not rule out that possibility. However, it matters little whether this is a direct quote or a problem that Plato's successors understood him as setting, or his work implying. Nor do I see any great difficulty in the fact that Geminus tells us:

"The Pythagoreans, who were the first to apply themselves to investigations of this kind, assumed the movements of the Sun, the Moon and the five planets to be circular and uniform. They would not admit, with reference to things divine and eternal, any disorder such as would make them move at one time more swiftly, at one time more slowly, and at another time stand still." ${ }^{49}$

What the Pythagoreans did not do is suggest offset axes for combinations of regular circular motions. That is the problem which Plato formulates, and which is first to be addressed by Eudoxus. Perhaps of greater concern is whether Plato could reasonably have issued this challenge, or could have been reasonably interpreted by close followers as having implied such a challenge ? Certainly he could have 
asked for regular circular motion, as I argued above. It is interesting that the Simplicius passage asks for ordered motion, as the Laws lays great emphasis on this, e.g. Laws 898a ff. advocates motion for the heavens which is 'according to one reason and order', while Laws $898 \mathrm{~b}$ contrasts motion which is regular and ordered with motion which is 'not regular or uniform and also motion which is not arranged or ordered or according to some reason. Certainly Plato might ask for hypotheses, and I see no problem in his asking for the phenomena to be saved. If the astronomy of the Timaeus was a prototype, then the challenge Simplicius reports makes good sense.

IX

It also makes good sense that Eudoxus developed this prototype, without being able to account fully for all the phenomena he was aware of. We are, after all, talking of the very early stages of development of the first serious astronomical model. The view that Eudoxus believed his model to be adequate to the phenomena has at times distorted our perception of Eudoxus as much as the correlate view of Plato. Mourelatos comments that:

"The notorious discrepancies between Eudoxus' model of homocentric spheres and the relevant data of planetary observation leads to a disjunctive conclusion: either Eudoxus' model was much more of an abstract kinematic exercise than is generally supposed; or Eudoxus had a rationalist-idealist conception of explanation which stipulated that empirical data are at best suggestive and, in any event defeasible. ${ }^{.50}$

I do not rule out the possibility that Eudoxus had slightly different beliefs to ourselves about the evidence or the relation of the evidence to the homocentric model. However, I see no reason to come to such radical conclusions as Mourelatos, as long a we are willing to countenance the idea that Eudoxus was developing a prototype, and as with many such developments, he was able to fix several but not all of the initial problems. Neugebauer comments that:

"Not only do we not have evidence for the numerical data in the construction of Eudoxus' homocentric spheres but it would also be difficult to understand how his theory could have survived a comparison with observational parameters. ${ }^{151}$ 
He goes on to say:

"This would be a confirmation of our impression that empirical data were not used to test the numerical consequences of the general cinematic construction. ${ }^{.52}$

So too Pannekoek says:

"It is evident that Eudoxus had not at his disposal sufficiently numerous and accurate observations with which to compare his theory and detect its inadequacy." 53

Again, I do not see any reason for such radical conclusions when all we have to suppose is that Eudoxus was developing a prototype. Neugebauer's comments might also lead us to puzzle over why Eudoxus was such a good stellar positional astronomer but took such a cavalier attitude to planetary astronomy, when there is no real need.

It is also important to remember that Eudoxus was a busy man (as indeed was Plato). Eudoxus was active in philosophy, geometry, mathematics, stellar as well as planetary astronomy, and later framed legislation for Knidos. We cannot be sure how much time he had to devote to planetary astronomy, or where it came on his list of priorities. It is quite possible that he made what contribution he could to planetary astronomy, while recognising its limitations, and then moved on to other projects.

We might also consider modern cosmology here. The original formulation of big bang cosmology was beset with problems well known to its instigators. The time scale was wrong by a factor of ten, there was no mechanism for the production of the heavy elements, there were no relics of an ancient hot, dense phase of the universe and there was no evidence of the predicted differential distribution of galaxies. Yet the idea had promise, was persevered with, and gradually these problems were solved. One might also note that in current big bang cosmology, there is a vast discrepancy between the amount of matter we can observe in the universe and the amount predicted by the theory.

Neither Plato, Eudoxus nor Callippus could account for all the phenomena they were aware of. I find that neither surprising nor unhealthy. Indeed, that is often the case in science and, I suspect, was very often the case in ancient astronomy. We do them a considerable disservice by assuming that they believed their theories were entirely adequate to the known phenomena. 
There are various ways in which one might try to drive a wedge between Plato and Eudoxus and so deny any influence from Plato to Eudoxus. Knorr comments that:

"It would thus be puzzling that Plato could on the one hand encourage Eudoxus to base his research on the principle of uniformity, yet not adhere to that principle in his own astronomical accounts. ${ }^{.54}$

Indeed it would, but we only need to be driven to the view that he does if we subscribe to the idea that Plato believed the model of the Timaeus could account for all the phenomena he was aware of. Once we recognise the Timaeus' astronomy as a prototype, then the insistence on RCM from many passages in the Timaeus can be allowed to stand.

One might try to argue that Plato gives a purely qualitative model while Eudoxus gives a quantitative one. However, Plato gives values for virtually all the available parameters of his model. The fixed stars rotate once a day, and there are periods for (or requests for values of) all the planets. He did not give a value for the inclination of the ecliptic, except to say that when the demiourgos formed the cosmos he formed the 'revolution of the different' (sun, moon and planets) and the 'revolution of the same' (the fixed stars) into the shape of the Greek letter chi. We do not know what value for the inclination of the ecliptic was used by Eudoxus and Callippus, though $24^{\circ}, 1 / 15$ of a circle, is commonly supposed. Indeed, we do not know that Eudoxus or Callippus gave precise values for all the parameters in their systems. It is quite possible that they realised that the hippopede could give qualitative explanations for some phenomena (retrogression, relation of Mercury and Venus to the sun) but were unable to formulate values which would give a precise match with the phenomena.

Goldstein and Bowen have argued that prior to Eudoxus, there were two traditions. There was that of the parapegmata, of those people interested in the risings and settings of stars, calendar construction and weather prediction. ${ }^{55}$ There was also the tradition of cosmological speculation, which Plato belonged to. They also argue that Plato and Eudoxus had somewhat different aims. The aim of Plato's astronomy, in common with the Pythagoreans being the explication of the ethical and 
aesthetical order of the cosmos, while Eudoxus sought a mathematical fit for the phenomena. Even if we accept Goldstein and Bowen's account, this, as they recognise, does not preclude Eudoxus having been influenced by Plato's cosmological speculation.

I have doubts as to whether we can make such a sharp distinction on either point. Plato uses precise values and furthermore asks for precise calculations. ${ }^{56}$ We do not know of the background views for Eudoxus and Callippus, so any supposition that they were not interested in the ethical and aesthetical order of the cosmos can only be an argument from silence. Moreover, they were both adherents of regular, circular and ordered motion, which might at least suggest they believed in some form of teleological ordering of the cosmos. It is also hardly unusual for astronomers after Callippus to see moral and aesthetic order in the cosmos. We might also see the first stirrings of a proper theory of planetary astronomy and a union between the observational astronomy and cosmological speculation in Plato. The offset axes of rotation give the first model where a fit with the phenomena is a serious issue. It is also notable in this context that the Timaeus comments that the periods of the planets other than sun and moon have not been discovered except by a few and that the Epinomis is also critical of Hesiod, and presumably the parapegmata tradition as well, praising those who have examined the orbits of the planets:

"The astronomer must be wisest, not as with astronomers like Hesiod and the rest, people who have studied only settings and risings, but someone who has studied seven of the eight orbits, each travelling through its own cycle in a manner not easily comprehended by anyone who does not have remarkable abilities." ${ }^{57}$

The alternative to an influence between Plato and Eudoxus is that they were independently influenced by Pythagorean ideas. ${ }^{58}$ That has to be a possibility, of course, but it does seem remarkable that two men who were in close proximity in space and time should both come up with the idea of offset axes for combinations of regular circular motion, and that one should produce a system which appears to be a logical development of the other, both in terms of complexity and sophistication and in terms of the phenomena that can be accounted for. If we add in the evidence of Simplicius, it seems much more likely that there was influence rather than independent discovery. 
Eudoxus is held by some to have been an instrumentalist. That is, he considered the theories he put forward to be merely the simplest available calculating devices for representing and predicting the phenomena. If, as seems likely, Plato held some form of realism, was this enough to exclude Plato being an influence on Eudoxus ? A variation on this theme is expressed by Knorr:

"Behind the details of their schemes, one can infer from Aristotle's account that Eudoxus and Callippus had engaged in a mathematical, not a cosmological, enquiry. ${ }^{159}$

Firstly, one must doubt whether we can simply label ancient thinkers as realists or instrumentalists. Secondly, even if Eudoxus were some form of instrumentalist, this does not preclude that he incorporated into his own instrumentally interpreted system or was influenced by some aspects of a model which Plato interpreted realistically. So too aspects of a cosmological enquiry might well influence those of a mathematical enquiry, even if we could make such a sharp distinction between Plato and Eudoxus, which I doubt. ${ }^{60}$ Thirdly, we might question whether Eudoxus was any sort instrumentalist of at all. The argument for Eudoxus being an instrumentalist is effectively an argument from silence. He did not specify how his spheres interacted in the manner of Aristotle, but simply gave a geometrical account, so he was an instrumentalist. It is important to recognise some differences between 'Aristotelian' and 'Platonic' realism. For Aristotle, there are the nested, interacting unrolling aethereal spheres. For Plato, planets are living entities having intelligence, executing the best motion they can. There is no need for interaction between spheres or systems of spheres, if each planet knows what it is doing. So did Eudoxus give the simplest formulation consistent with saving the phenomena ? Certainly not. Rather than having one daily circular motion common to the stars and all of the planets, each planet had a full system of individual motions. That is consistent with a Platonic realism, but not instrumentalism. Eudoxus was aware of at least some inadequacies in his system. If his primary goal was saving the phenomena, as instrumentalism demands, then either he should have made some ad hoc modifications, thus wrecking RCM, or he should have rejected homocentric spheres entirely. That Eudoxus stayed with RCM was again consistent with Platonic realism, but not instrumentalism. It is also compatible with Plato's cosmological views but not a purely mathematical approach. We have no grounds for supposing that Eudoxus, or Callippus, were instrumentalists other 
than the argument from silence. That argument does not discriminate between a Platonic realism and instrumentalism.

\section{XII}

Owen proposed a relatively early dating for the Timaeus. In doing so, he argued that any influence from Eudoxus came after that Timaeus but before the Laws and that Eudoxus died in 356-353, the date given by Apollodorus. ${ }^{61}$ The fact that Plato resorted to the contrary power in relation to Mercury and Venus, according to Owen, was enough to show that Eudoxus had no influence on the Timaeus. Owen finds it tempting to see an acknowledgement of Eudoxus' solution in the Laws denial of wandering motion for the planets, as he believes that the Timaeus accepts wandering in the sense of 'arbitrary variations in speed and direction' ${ }^{62}$ While I would agree with Owen that Plato does change his views on this matter, I argue that this change occurs between the Republic and the Timaeus. I would also reject the notoriously unreliable testimony of Apollodorus, and accept a much later date for the death of Eudoxus, possibly 342 or $337,,^{63}$ both after the death of Plato in 348 . In which case, even if we date the Timaeus relatively late, Eudoxus would have had plenty of time to develop concentric sphere astronomy even if he began after the writing of the Timaeus.

I agree with Owen that Plato's use of the contrary power indicates that he was not conversant with the final system of Eudoxus when he wrote the Timaeus. ${ }^{64}$ However, we do not know when Eudoxus began his work on concentric sphere astronomy and when he finished it. It is quite possible Plato was only aware of it in an early and developmental form, and Eudoxus completed it either after leaving Athens or after Plato's death.

We know virtually nothing of the relationship between Plato and Eudoxus. There is nothing that compels us to suppose any influence was in one direction only. Perhaps Eudoxus' idea of homocentric spheres (in some stage of its development) influenced Plato, leading him to drop the idea of wandering planetary motion and to adopt offset axes in the Timaeus. Perhaps Plato's own idea of offset axes, and the challenge mentioned by Simplicius inspired Eudoxus. Two points may indicate some further interaction between the two. It seems highly likely that Plato's attack on the notion that 'pleasure is the good' in the Philebus was aimed at Eudoxus. It may well also be the case that aspects

of Eudoxus' mathematics influenced Plato in the Philebus. ${ }^{65}$ We need not suppose that any interaction 
was friendly, either. Eudoxus may have taken up the challenge to account for the motions of the heavens with RCM in a competitive rather than a co-operative manner, seeking to outdo Plato. ${ }^{66}$ In the absence of any further evidence, we have to go with the existing texts. So Plato gives us the first extant account of a path for the planets offset from the daily motion of the fixed stars, and that was a significant step forward in astronomy.

\section{XIII}

We might try to separate Plato and Eudoxus on the grounds of radically different attitudes to the phenomena. There is of course the Republic VII passage where Plato has Socrates say:

"It is by means of problems, then, that we shall proceed with astronomy as we do geometry, and we shall leave the things in the heavens alone, if we propose by really taking part in astronomy

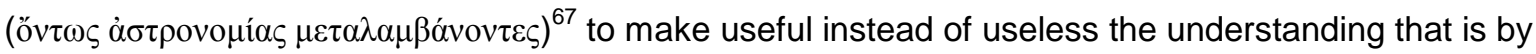
nature in the soul."

Some commentators have detected a rejection or denigration of the phenomena here. ${ }^{69}$ In my view this passage is harmless. ${ }^{70}$ Plato generates a distinction between how astronomy is done, how it is now taught for the purposes of philosophical education, and how it ought to be taught to the prospective guardians in order to further their philosophical development. ${ }^{71} \mathrm{He}$ then draws the entirely unsurprising conclusion that if we wish to further the intellectual development of the guardians by using astronomy, it ought to be by a contemplation of problems rather than observation of the phenomena. He says nothing here of how astronomy ought to be done, indeed the implicit contrast is that observation should be a part of how astronomy is done. That gives Plato a reasonable view rather than a ludicrous one, fits better with the conception of investigation implicit in the epistemological allegories of sun, line and cave and makes better sense of the comment that 'our eyes are framed for astronomy, and our ears for harmony' at 530d. However we take the Republic, the Timaeus says that:

"Sight, in my opinion, is the cause of the greatest benefit to us as not a word of our current account of the universe could ever have been given if neither the stars, the sun, nor the heavens had been seen. But now the sight of day and night, of months and the cycle of the years has procured for 
us number and the concept of time, and has also led us to seek the nature of the universe. From these we have derived philosophy, and no greater good has or will come as a gift from the Gods to mortal men... God devised and gave to us vision in order that we might observe the rational revolutions of the heavens and use them against the revolutions of thought that are in us, which are like them, though those are clear and ours confused, and by learning thoroughly and partaking in calculations correct according to nature, by imitation of the entirely unwandering revolutions of God we might stabilise the wandering revolutions in ourselves." ${ }^{, 72}$

Whether this involves a change of position, or change of emphasis from the Republic or not, the Timaeus seems clear. ${ }^{73}$ Observation of the heavens is crucial, and as Vlastos puts it, the language of the Timaeus is 'saturated with the terms of observational astronomy'. ${ }^{74}$ So too the Timaeus is keen on precise calculations in astronomy (40c, 47c), visual models of the heavens (40d), and praises those few men who have noted the periods of all the planets (39c).

Such a position, I would argue, is entirely in accord with Plato's conception of techne. A necessary, but not sufficient condition for possessing a techne is having mastered the empirical basis

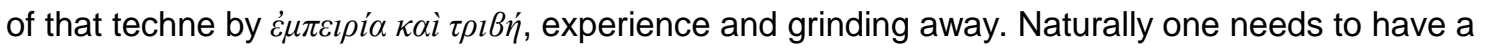
synoptic mastery of the intellectual elements of each techne as well before one could be said to possess it fully, but the empirical basis needs to be grasped as well. ${ }^{75}$ This conception of techne can be found across many works (e.g. Gorgias, Phaedrus, Timaeus, Laws) and across many subjects (e.g. rhetoric, medicine, music) ${ }^{76}$

The Epinomis has a very positive attitude to the observational records of the Egyptians and Syrians:

"The first to observe these bodies was a non-Greek. Tradition nurtured those who first took these things to mind, due to the excellence of the summer season which both Egypt and Syria adequately possess, and revealed to their sight, so we say, they always beheld the stars together... These observations have since disseminated everywhere and have been shown to be true by the test of time." ${ }^{77}$ 
So too, as we saw earlier, the Epinomis is critical of those who only study certain phenomena and not all of the planetary orbits. I see no grounds to preclude a significant interaction between Eudoxus and Plato on the basis of differences in attitude to the phenomena.

\section{XIV}

The astronomy of the Timaeus was a significant advance on its predecessors. Instead of one axis of circular motion, we find the key idea that the motions of the heavens can be explained by combinations of regular circular motions with offset axes of revolution. This model was a prototype. Plato was unable to account for all, indeed many of the phenomena that he was aware of with this model. It was strong on cosmological principle but much weaker on astronomical application. On this reading, the challenge recorded by Simplicius makes good sense. The relation of Callippus to Eudoxus seems similar to that of Eudoxus to Plato. Both increase the complexity and sophistication of the previous model, while remaining within the principles of the programme, and both seek to solve the key problems of the previous model. Neither Eudoxus nor Callippus were able to account for all the phenomena that they were aware of either. There were no significant philosophical differences between Plato and Eudoxus that which would rule out a fruitful liaison between them. On my reading, Plato advocated RCM in the Timaeus, but lacked the means to solve many problems in astronomy which Eudoxus and Callippus later provided. There were no major differences in attitudes to the phenomena, nor on the question of realism/ antirealism, and Plato's model, while naturally much less sophisticated than that of Eudoxus, had values for most of its parameters. If we reject Apollodorus in favour of later dates for Eudoxus' death, there are no dating problems either. This gives us a very smooth history of the planetary astronomy of this period, Plato, Eudoxus and Callippus all making significant contributions and building on the work of their predecessors. The Timaeus had an important influence on subsequent astronomy in presenting a prototype of models with offset angles of rotation for RCMs. 
${ }^{1}$ Most notably J. Mittlestrass, Die Rettung der Phenomena, Berlin (1963), W. R. Knorr, 'Plato and Eudoxus on the Planetary Motions', Journal for the History of Astronomy xxi, (1990) 313-329, L. Zhmud, 'Plato as "Architect of Science"', Phronesis 43/3 (1998) 211-244.

${ }^{2}$ See Aristotle De Caelo 293a18ff., cf. Metaphysics 986a.

${ }^{3}$ See Plato, Republic $616 \mathrm{~b} f \mathrm{f}$.

${ }^{4}$ Ignoring the motion of the earth's axis of rotation, the effect of which (the precession of the equinoxes) had yet to be discovered.

${ }^{5}$ One can also have good explanations of the phases of the moon and the periods of the planets, but previous models had managed these as well.

${ }^{6}$ See below for further explanation.

${ }^{7}$ For more detailed argument on this issue see A. D. Gregory, Plato's Philosophy of Science (London 2000) 105-109.

${ }^{8}$ They are specifically $\dot{\alpha} \pi \lambda \alpha v \varepsilon ́ \varsigma(34 \mathrm{a} 5,40 \mathrm{~b} 4)$.

${ }^{9}$ Cf. Republic 529d ff.

${ }^{10}$ Note the difference between the $\sigma 0 \mu \mu \varepsilon \tau \rho i ́$, 'proportions' at Republic 530a7 which deviate, and the

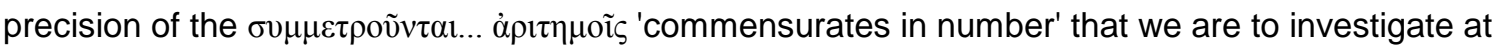
Timaeus 39c7.

${ }^{11}$ Laws 822a: "The usual opinion concerning the sun, moon, and other planets, that they at some time wander ( $\pi \lambda \alpha v \tilde{\alpha} \tau \alpha 1)$, is not the case; precisely the opposite is true. For each of these bodies always travel on one path, and not many, although this may not seem so." I accept that the Laws was 'on the wax' when Plato died and was subsequently 'published' (and edited ?) by Philip of Opus, who also 'published' (and edited/ wrote ?) the Epinomis. Quite possibly he had a greater hand in the creation of the Epinomis. With due caution, I take it to be indicative of at least what a close associate of Plato thought ought to be an appendix to the Laws, and so reflects views of Plato or someone who immediately followed him.

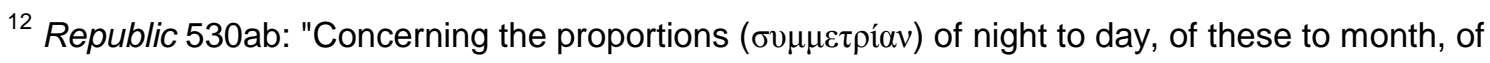
month to year, and of the other stars to these and each other, wouldn't he consider it absurd to expect these things always to behave in the same manner and never to deviate ( $\pi \alpha \rho \alpha \lambda \lambda \dot{\alpha} \tau \tau \varepsilon v v)$ in any way ?" 
In the phase of the myth of the Politicus in which we live, the cosmos is degenerating towards chaos, and so the heavenly motions become chaotic.

${ }^{13}$ Cf. Republic 616b, Politicus 270a9 and Timaeus 34a, also Timaeus 33d. It is interesting that Plato moves from a supported to an unsupported cosmos (cf. the presocratics and what supports the earth), and it is also arguable that he moves from a degenerating to a stable cosmos (see Gregory (n.7) 101113).

${ }^{14}$ Timaeus 38d2-4.

${ }^{15}$ See F. M. Cornford Plato's Cosmology (London 1937) p. 137, Knorr (op. cit. note 1) 315-137.

${ }^{16}$ Simplicius in De Caelo $504.17 \mathrm{ff}$.

${ }^{17}$ Depending on its distance from the earth, the moon sometimes covers the entire sun, while sometimes a small rim of the sun is visible around the moon. The latter is an annular eclipse.

${ }^{18}$ The Loeb text omits these words, without comment, and for no good reason. They are in Burnet's Oxford text and are omitted in only one of the sources. Other passages demonstrating Plato's knowledge of solstices and equinoxes are at Phaedo 98a, Laws 767cd and 945e and Epinomis 990b.

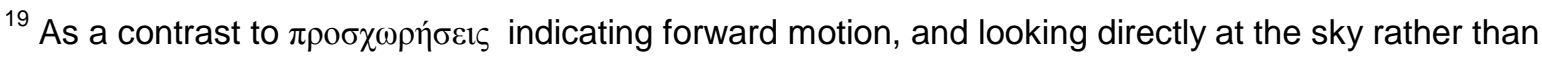
at setting positions on the horizon.

${ }^{20}$ Cf. Republic 617b2.

${ }^{21}$ It also has the technical meaning of conjunction in later works.

${ }^{22}$ In fact, their motion is retrograde relative to the fixed stars for only a small proportion of the time it is retrograde relative to the sun.

${ }^{23}$ See A. E. Taylor A Commentary on Plato's Timaeus (Oxford 1928) 196-202, see also G. L. Vlastos Plato's Universe (Washington 1975) 58.

${ }^{24}$ See e.g. Laws 898a ff., Epinomis 991e.

${ }^{25}$ For the latest reconstructions of what can be done with the systems Eudoxus and Callippus see I. Yazetz, 'On the Homocentric Spheres of Eudoxus', Archive for the History of the Exact Sciences 52 (1998) 239-243, H. Mendell, 'Reflections on Eudoxus, Callippus and their Curves: Hippopedes and Callippopedes', Centaurus 40 (1998) 188-194. 
There is a further standard problem of Mercury and Venus in relation to the sun. While centring a hippopede in the sun gives bounded elongation, it gives a poor match for the movement of Mercury and Venus relative to the sun.

${ }^{26}$ Later evidence gives $0.5^{\circ}$ as the value for the sun's deviation, $5^{\circ}$ is a standard ancient value for the moon's deviation from the ecliptic.

${ }^{27}$ See Simplicius in De Caelo $494.23 \mathrm{ff}$.

${ }^{28}$ That is we transpose both speed and direction of rotation, as the third sphere rotates in the opposite direction to the second.

${ }^{29}$ L. Ideler Abhandlungen der Berliner Akadamie, Hist-phil. (1828) 189-212 \& Abhandlungen der Berliner Akadamie, Hist-phil. 49-88 Schiaperelli ‘Le Sfere Omocentriche di Eudosso, di Callippo et di Aristotele', Publicazioni del R. Observatorio di Brera in Milano ix (1875), see also J. L. E. Dreyer, History of the Planetary Systems (Cambridge 1906) 91-93, T. Heath, Aristarchos of Samos (New York 1913) 196-198, D. R. Dicks, Early Greek Astronomy to Aristotle (Bristol 1970), V. E. Thoren, 'Anaxagoras, Eudoxus, and the Regression of the Lunar Nodes', Journal for the History of Astronomy ii (1971) 23-28, O. Neugebauer, A History of Ancient Mathematical Astronomy (Berlin 1975) 624-626, Yavetz (n.25) and Mendell (n.25). Also of interest is E. Maula, Studies in Eudoxus' Homocentric Spheres (Helsinki 1974).

${ }^{30}$ The moon will be north or south of the line through the middle of the zodiac for half the period of the third sphere. If we assume that the second sphere rotates in roughly one month, then as the third sphere rotates much more slowly the moon cannot go though its latitude cycle in around one month (though see below on Mendell and whether we should accept this assumption for the second sphere). The figures which work best for the modern interpretation are 223 months for the second sphere and one month for the third, 223 months being the cycle of lunar eclipses. If we transpose those figures to the Aristotle/ Simplicius interpretation, then the moon will be north or south of the line through the middle of the zodiac for 9 years.

${ }^{31}$ This would be the best value for this system, and it is possible that Eudoxus was aware of the 223 month cycle of lunar eclipses.

32 Dicks (n.29) 178-181. 
${ }^{33} \mathrm{~A}$ node is where the moon passes through the ecliptic. As Eudoxus did not have the idea of the ecliptic (he had either the line of the sun's motion or the line through the middle of the zodiac), technically he could not have had the modern conception of a node. I don't see that it would be that hard for Eudoxus to arrive at something like the idea of a node from a consideration of the phenomena he was aware of and the consequences of the three sphere system. On this see Thoren (n.29).

${ }^{34}$ Mendell (n.25) 267 n21.

${ }^{35}$ I would agree Mendell (n.25) $267 \mathrm{n} .21$ that if the three sphere model is meant in some way to account for variations in the speed of the moon through the zodiac, it is hard to se why Callippus adds two extra spheres.

${ }^{36}$ We would need to give up the idea that the second sphere rotates roughly once a month. It might rotate significantly faster than that, the extra motion along the line of the zodiac being counteracted by a faster speed for the third sphere which rotates in (nearly) the opposite direction. This would allow a much better account of latitudes and nodal motion, and although both spheres would be rotating quickly, the second would still be rotating much quicker than the third, in line with Simplicius.

${ }^{37}$ See G. E. R. Lloyd, Aristotelian Explorations (Cambridge 1996) 160-183, A. D. Gregory, 'Plato and Aristotle on Eclipses', Journal for the History of Astronomy xxx pp. 245-249.

${ }^{38} \mathrm{~A}$ further difficulty is this. With modern mathematical methods, and computer simulations we are now more aware than ever of what the possibilities inherent in the homocentric sphere system were. However, to what extent were Eudoxus and Callippus aware of these possibilities ?

${ }^{39}$ We do not even know which phenomena they principally considered. The older assumption was retrograde motion, but that has recently been challenged. One can give values which give the best fit for retrograde motion, but then the other phenomena suffer. One can set up the values in the systems of Eudoxus and Callippus with other phenomena, such as times of invisibility being saved first, when retrograde motion suffers.

${ }^{40}$ See Hipparchus in Arati et Eudoxi. I,9, who quotes from the lost Enoptron of Eudoxus.

${ }^{41}$ See Simplicius in De Caelo $493.15 \mathrm{ff}$.

${ }^{42}$ Going back to the value of $24^{\circ}$ for the inclination of the zodiac, it might also help to explain the position of some eclipses.

${ }^{43}$ Simplicius in De Caelo $488.18 \mathrm{ff} .$, my bracketed sections. 
${ }^{44}$ Simplicius in De Caelo $492.31 \mathrm{ff}$.

${ }^{45}$ Mittlestrasse (n.1) 149 ff., Knorr (n.1) 319-321, Zhmud (n.1) 127-218.

${ }^{46}$ Vlastos (n.23) 110-111.

${ }^{47}$ Zhmud (n.1) 218.

${ }^{48}$ Regular, ordered, circular, regular and ordered, circular, regular and ordered, regular, circular and ordered, and perhaps five if we count 488.13 'simple, circular, regular and ordered' ( $\dot{\alpha} \pi \lambda \tilde{\alpha} \varsigma \kappa \alpha \grave{~}$

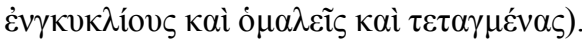

${ }^{49}$ Geminus, Isagoge I, 19-21.

${ }^{50}$ A. P. D. Mourelatos, 'Astronomy and Kinematics in Plato's Project of Rationalist Explanation', Studies in the History and Philosophy of Science 12 (1981) 1-32, p. 1.

${ }^{51}$ Neugebauer (n.29) 675.

${ }^{52}$ Neugebauer (n.29) p. 679.

${ }^{53}$ A. Pannekoek, A History of Astronomy (New York 1961), 111.

${ }^{54}$ Knorr (n.1) 321.

${ }^{55}$ See B. R. Goldstein and A. C. Bowen, 'A New View of Early Greek Astronomy', Isis 74 (1983) 330340.

${ }^{56}$ See Timaeus 47c, see also Laws 967ab "Even at that time a sense of wonderment emerged concerning the heavenly bodies, and those who studied them accurately suspected what is now indeed believed, that if they were soulless and lacking in intelligence, they would not be amenable to

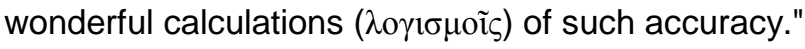

${ }^{57}$ Epinomis 990a ff.

${ }^{58}$ A view held Zhmud (n.1) 229.

${ }^{59}$ Knorr (n.1) 323.

${ }^{60}$ See my earlier comments on quantitative and qualitative explanations in Plato and Eudoxus.

${ }^{61}$ G. E. L. Owen, 'The Place of the Timaeus in Plato's Dialogues', Classical Quarterly NS 3 (1953) 75$95,86-87$.

62 Owen (n.61) 87.

${ }^{63}$ F. Gisinger, 'Die Erdbeschreibung des Eudoxus von Knidos', Stoicheia Heft 6, (1921) 5/6, places

Eudoxus' death in 342, and both de G. Santillana, 'Eudoxus and Plato', Isis 32 (1949) 248-262 
and F. Laserre Die Fragmente des Eudoxus von Knidos (Berlin 1966) 137-142 give 337, after Plato's death in 348. There is also the problem of accommodating the evidence of Pliny (Natural History XXX, 3) who talks of Eudoxus dating Zoroaster as living 6,000 years before the death of Plato, implying that Eudoxus outlived him.

${ }^{64}$ Owen (n.61) 87. I agree with Owen against Cornford (n.15) 116 that there is no indication of Eudoxus at $39 \mathrm{~cd}$.

${ }^{65}$ See K. M. Sayre Plato's Late Ontology (Princeton 1983) 71-74, 105-113, 144-46 on the Dedekind cut, Eudoxus and possible influences on Plato.

${ }^{66}$ My thanks to Dr. Peter Adamson for this point.

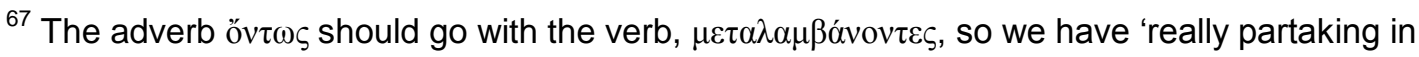
astronomy', not with $\dot{\alpha} \sigma \tau \rho o v o \mu i ́ a \varsigma$ ('partaking in real astronomy)'.

${ }^{68}$ Republic 530b6-c1.

${ }^{69}$ Eg. Heath (n.29) 135 note 2, 139, cf. Mittlestrass (n.1) 117, O. Neugebauer, The Exact Science in Antiquity (Providence 1957) 157.

${ }^{70}$ See Gregory (n.7) Ch. 2 for further details.

${ }^{71}$ See eg. Republic 529c4-6.

${ }^{72}$ Timaeus 47a ff.

${ }^{73}$ In my view Timaeus 68b-d (on colours, fire particles and what humans can know) does not support the idea that Plato denigrated observation either. See Gregory (n.7) 67-73.

${ }^{74}$ Vlastos (n.23) 50. Vlastos is referring specifically to Timaeus 40c4-d3.

${ }^{75}$ See Gregory (n.7) 49-51.

${ }^{76}$ See Gregory (n.7) 67-73, 171-73, 262-64.

${ }^{77}$ Epinomis 986e6-987a6. 